\title{
Imagen de la paternidad en los médios impresos: análisis documental
}

\section{Image of fatherhood in printed media: document analysis \\ Imagem da paternidade na mídia impressa: análise documental}

Maria Beatriz de Assis Veiga ${ }^{1}$ Alyne Corrêa de Freitas ${ }^{2}$ Simone Aguiar ${ }^{3}$ Nayara Araújo de Souza ${ }^{4}$

Fernando Porto ${ }^{5}$ Adriana Lemos ${ }^{6}$

${ }^{1}$ Mestre em Enfermagem pelo Programa de Pós Graduação em Enfermagem da Universidade Federal do Estado do Rio de Janeiro (UNIRIO).

${ }^{2}$ Doutoranda do Programa de Pós-graduação Doutorado em Enfermagem e Biociências.

${ }^{3,4}$ Enfermeira da Estratégia da Saúde da Família do Município do Rio de Janeiro.

${ }^{5}$ Professor Associado da Escola de Enfermagem Alfredo Pinto, Doutor em Enfermagem, Coordenador do Programa de PósGraduação Mestrado em Enfermagem -UNIRIO.

${ }^{6}$ Professora Associada da Escola de Enfermagem Alfredo Pinto, Doutora em Saúde Coletiva, Coordenadora do Curso do Programa de Pós-Graduação de Mestrado em Enfermagem - UNIRIO.

Cómo citar este artículo en edición digital: Veiga, M.B.A., Freitas, A.C., Aguiar, S., Souza, N.A., Porto, F., \& Lemos, A.. (2017).

Imagen de la paternidad en los médios impresos: análisis documenta. Cultura de los Cuidados (Edición digital), 21(48). Recuperado de < http://dx.doi.org/10.14198/cuid.2017.48.20>

Correspondencia: Maria Beatriz de Assis Veiga. Av. Pasteur, 296 - Urca - Campus 296 Prédio da Enfermagem, $5^{\circ}$ piso. CEP 22290-240. Rio de Janeiro (RJ)-Brasil.

Correo electrónico: maribi.v@uol.com.br

Recibido: 04/01//2017; Aceptado: 10/04/2017

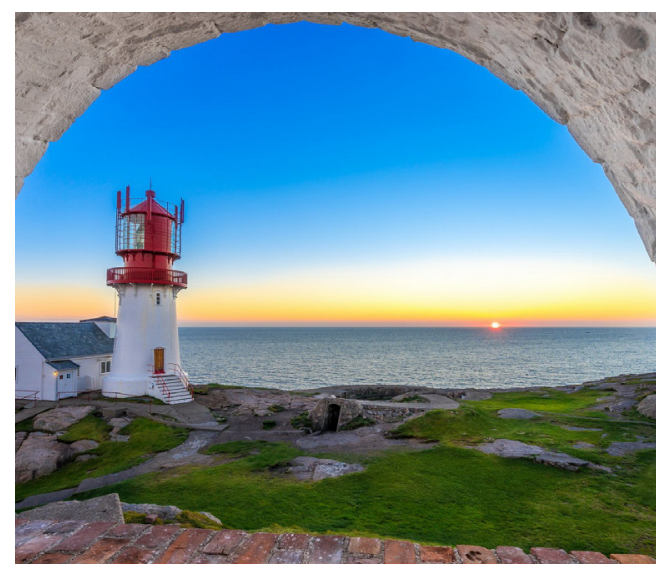

\section{ABSTRACT}

Aim: to identify the media records of the press communication representing paternity and to comment how they represent the father approaching his commemorative day.

Method: exploratory study, carried out through documental analysis, by means of "O GLOBO" newspaper, from August 01 to 11, 2013, some days before the Father's day.
Result: 106 media records were identified: $66,26 \%$ advertising records and $37,73 \%$ reports. The father figure appeared on every day of this time delimitation.

Discussion: paternity occurred amidst sociocultural and gender issues that permitted to perceive today a father figure more affective and involved on the child care.

Conclusion: There is a business investment around the father figure, nevertheless, not only commercial factors, but also cultural and social ones influence on practicing paternity.

Descriptors: Paternity; Gender and Health; Reproductive Rights; Man Health

\section{RESUMEN}

Objetivos: identificar los registros mediáticos de los medios de comunicación impresa que representen la paternidad y analizar los comentarios acerca de día del padre.

Método: estudio exploratorio realizado por análisis documental, en el periódico “ $\mathrm{O}$ 
Globo" en período de 01 a 11 de agosto de 2013, día que antecede a la conmemoración al día de los padres. Resultado: 106 registros mediáticos fueron identificados, siendo 66,73\% de reportajes. La figura paterna apareció en todos los días de la delimitación temporal.

Discusión: la paternidad ocurrió en medio a cuestiones socioculturales y de género que permitieron percibir la figura padre actualmente más afectuoso e involucrado en el cuidado del el hijo.

Conclusión: Existe incidencia empresarial en la imagen paterna, sin embargo, no solo factores comerciales sino también culturales y sociales influyen en el ejercicio de la paternidad.

Descriptores: Paternidad, Género y Salud, Derechos y Reproductivos, Salud del hombre.

\section{RESUMO}

Objetivos: identificar registros midiáticos da comunicação impressa que representem a paternidade, e comentar como eles apresentam o pai nas proximidades de sua data comemorativa.

Método: estudo exploratório, realizado por análise documental, por meio do jornal “O GLOBO”, no período de 01 a 11 de agosto de 2013, dias que antecederam a comemoração do Dia dos Pais.

Resultado: 106 registros midiáticos foram identificados, sendo $66,26 \%$ de publicidades e $37,73 \%$ de reportagens. A figura paterna apareceu em todos os dias da delimitação temporal.

Discussão: a paternidade ocorreu em meio a questões socioculturais e de gênero que permitiram perceber a figura de um pai atualmente mais afetivo e envolvido no cuidado com o filho.

Conclusão: Existe investimento empresarial em torno da imagem paterna, no entanto, não só fatores comerciais, mas também culturais e sociais influenciam no exercício da paternidade.

Descritores: Paternidade; Gênero e Saúde; Direitos Reprodutivos; Saúde do Homem

\section{INTRODUÇÃO}

O fortalecimento do movimento feminista ocorrido na década de 70 , foi fundamental para que as mulheres conquistassem direitos e trouxe à tona discussões relacionadas ao gênero. Com isso, buscou-se compreender melhor o homem e a masculinidade. Isto implica em se rever questões relacionadas aos aspectos emocionais, culturais, religiosas e familiares que norteiam a vivência da paternidade. Assim, a relação filho-pai-filho é influenciada pelo entendimento da masculinidade(Freitas, Coelho e Silva,2007).

Alguns estudos (Beltrame e Bottoli,2010; Bustame,2005; Freitas, Coelho e Silva,2007; Oliveira e Silva,2005), apontam para a vivência da paternidade embasada no modelo tradicional de pai, pouco envolvido com a gestação, preocupado com o provimento material do lar, mas, também, apresentando características da nova paternidade representada por maior envolvimento com o filho, o que traduz a possibilidade de transformação das relações de gênero e (re)construção das atribuições maternas e paternas.

Ser pai é "uma construção contínua, plural e sempre em aberto, que se processa nesta tensão cultura/indivíduo" (Hennigen e Guareschi,2002:45) .Por ser uma vivência dinâmica, essa construção sofre modificações ao longo do tempo, promovendo transformações na vida conjugal e na maneira de se relacionar com o mundo. Além disto, deve ser fundamental a construção da identidade do filho, 
tendo por referencial a figura paterna(Oliveira e Silva,2005).

A questão da paternidade transcende os limites da família, abrangendo o campo de debate na área da saúde sexual e reprodutiva, pois a maternagem e a paternagem são de responsabilidade de ambos os sexos (Freitas, Coelho e Silva,2007).Isto implica, no exercício da paternidade, como uma das possibilidades do homem cuidar de si próprio, dos filhos e da parceira.

Nesta perspectiva, ao abordar os aspectos de gênero, o campo da saúde pode colaborar em possíveis mudanças no exercício da paternidade na sociedade. Com efeito, aprofundar o conhecimento a respeito dos aspectos que as envolvem, torna-se necessário para a inserção do homem neste espaço de experiências em andamento (Bustame,2005; Oliveira e Silva,2005). Isto posto, o campo da saúde potencializa a sensibilidade para inclusão do pai no cuidado à criança, já que este é majoritariamente exercido pela figura materna (Crepaldi et al,2006).

Sabe-se, até o momento, que a primeira homenagem ao pai foi registrada na Babilônia há 4 mil anos, quando um jovem teria feito para seu pai um cartão modelado em argila, desejando-lhe saúde e sorte, o que se acredita ter se consagrado tal iniciativa como o primeiro registro de homenagem aos pais na história da Humanidade. Outra possível versão de origem da data deu-se nos Estados Unidos da América onde o Dia dos Pais foi comemorado, a princípio, em 1910, quando a filha um membro da artilharia First Light Arkansas que lutou em 1862 na Batalha de PeaRidge, durante a Guerra Civil, homenageou seu pai, e este fato credenciou a data, que se espalhou pelo mundo. (Portal G1,2013)

Em 1966, o terceiro domingo de junho foi designado oficialmente como Dia dos Pais naquele país e, em 1972, tornou-se feriado nacional. Atualmente, a data é comemorada em 70 Nações. Por outro lado, em países de maior tradição católica, como Portugal e Espanha, as homenagens aos pais ocorrem em 19 de março, dia de São José, marido de Maria, mãe de Jesus (Portal G1,2013).

Mediante o exposto, acredita-se na possibilidade de que o Dia dos Pais seja uma expressão aplicada por alguns historiadores, denominada tradição inventada, entendida como "processo de formalização e ritualização, caracterizado por referir-se ao passado, mesmo que apenas pela imposição da repetição" (Hobsbawm e Ranger, 1984:12).

Com o propósito de fortalecer os laços entre as famílias, o publicitário Sylvio Bhering, na ocasião diretor do Jornal O GLOBO e da Rádio Globo, instituiu em 14 de agosto de 1953 o Dia dos Pais no Brasil, na mesma data em que se comemorava o dia de São Joaquim, pai de Maria, considerado o patriarca da família. A iniciativa foi um sucesso, tanto assim que no segundo ano não apenas o Rio de Janeiro comemorava a data, bem como boa parte do Brasil também o fazia. Nos anos posteriores, em analogia ao Dia das Mães comemorado no segundo domingo de maio, esta celebração passou a ocorrer no segundo domingo de agosto.( O Globo,2014)

Estudo visando explorar a paternidade por meio da análise de comerciais de televisão, teve por objetivo compreender as diversas faces da paternidade na cultura (Hennigen e Guareschi,2002). Assim, destacou que a mídia é um dos meios de circulação de discursos para a construção de identidades, citando que isso poderia potencializar a compreensão mais ampla da temática, considerando fundamental buscar os significados que circundam o tema, a exemplo dos aspectos culturais. 
Neste sentido, percebe-se que a mídia, além de disseminar conhecimentos na comunidade, influencia na formação de senso crítico, podendo contribuir para a revisão de valores e atributos socialmente preestabelecidos. Nessa linha de raciocínio, acredita-se ainda que compreender os sentidos da paternidade possa propiciar o estabelecimento de políticas públicas que norteiem as práticas da saúde sexual e reprodutiva (Campos, Melo e Farias,2012).

A construção deste estudo partiu do referencial teórico, a saber: "A ética do cuidado", na perspectiva de Carol Gilligan; Esta autora, é uma das pioneiras do enfoque da temática "ética do cuidado", e descreveu duas abordagens diferenciadas para assunção de decisões morais, que correspondem às identidades feminina e masculina, e são construídas desde a infância e se mantem na vida adulta, sendo vistas como pares e complementares, e não a primeira submissa à segunda. $\mathrm{Na}$ visão de Gilligan, a voz masculina é voltada a propostas éticas embasadas na imparcialidade e nos direitos, enquanto a feminina baseia-se nas relações e no cuidado (Marinho,2004; Kuhnen,2010;Zoboli,2004). Gilligan defende ainda que nas sociedades ocidentais, a abordagem masculina quanto à moralidade impõe limites, teme as relações de intimidade e orienta para a "justiça", priorizando o "eu" e a independência, sendo menos centrada no cuidado; a abordagem feminina, por sua vez, centra-se na visão de que as pessoas têm responsabilidades umas com as outras, preocupando-se com o cuidado e privilegiando a interação.( Marinho,2004)

Considerou-se também para a elaboração do presente estudo, que a imagem pertencente a dois domínios, sendo representada na esfera visual por meio de desenhos, pinturas, gravuras, fotografias, dentre outros, assim composta por objetos materiais, e na esfera mental é representada de forma imaterial, aparecendo em nossas mentes como visões e imaginações, e esses dois domínios articulados, visual e mental, a constituem.(Santaella e Noth,2008)

Mediante o exposto, este estudo norteou-se pela seguinte questão: Como a paternidade é representada pela mídia impressa? Objetivando assim: identificar registros midiáticos da comunicação impressa que representem a paternidade, e comentar como eles apresentam o pai nas proximidades de sua data comemorativa.

\section{MÉTODO}

Trata-se de pesquisa qualitativa, exploratória, por visar proporcionar maior familiaridade com o problema. Empregou-se como técnica a análise documental (Gil,2008). Para tanto, optou-se por documentos midiáticos impressos para tratamento analítico, visando atender à questão norteadora do estudo e seus objetivos.

A coleta de dados foi realizada no período de 01 a 11 de agosto de 2013, através de registros midiáticos diversos que veiculassem o tema da paternidade no jornal impresso "O Globo”. A delimitação temporal foi estabelecida por contemplar as publicações do início daquele mês até a data em que se comemora, no Brasil, o "Dia dos Pais". A escolha do jornal justifica-se pelo fato de a Associação Nacional de Jornais (Associação Nacional de Jornais,2013) classificá-lo como sendo o de maior circulação na cidade do Rio de Janeiro. Considerou-se, também, o fato de ter o noticiário supracitado contribuído significativamente para o estabelecimento da data comemorativa do Dia dos Pais no Brasil.( O Globo,2014)

Para estabelecer a pré-análise, buscou-se encontrar registros midiáticos que veiculas- 
sem a temática da paternidade, os quais foram aplicados a uma matriz de análise composta pelos seguintes itens: data de publicação, sessão do jornal, titulo do registro midiático, com ou sem a presença de imagens, síntese do conteúdo do registro, tipificação do registro midiático e observações pertinentes do nexo com o objeto de estudo.

Cabe esclarecer que para se tipificar os registros midiáticos, considerou-se como reportagem o texto narrativo da realidade factual ritmada pelo cotidiano (Sodré e Ferrari,1986);e publicidade, como "promoção comercial que visa o consumo de bens, mercadorias ou serviços"( Marshall,2003:102).

O tratamento dos dados foi contemplado pela análise de conteúdo, metodologia recorrente nos casos de análise documental, culminando em normas sistemáticas para extrair os significados temáticos contidos no texto e apreendidos pelo leitor(Sá-Silva, Almeida e Guindani,2009).
A exploração do material realizou-se a partir da leitura minuciosa das matérias já selecionadas e posteriormente decodificadas, conforme a convergência dos temas abordados, assim estabelecendo-se as quatro categorias apresentadas a seguir.

\section{RESULTADOS}

Após a coleta dos dados e aplicação da matriz de análise aos registros midiáticos delimitados pela proposta do estudo, foi possível atender ao primeiro objetivo: identificar matérias nos meios de comunicação impressa, que representassem a paternidade. As matérias são apresentadas no gráfico 1 , conforme o dia de veiculação do registro midiático, o tipo de material e a presença ou ausência de imagem.

Foram identificados, no total, 106 registros midiáticos, sendo 66 publicidades $(62,26 \%)$ e 40 reportagens (37,73\%). Destes, 64 (96,97\%) destinaram-se a publicidades com imagens, e 26 (65\%), a reportagens com imagens (Gráfico 1).

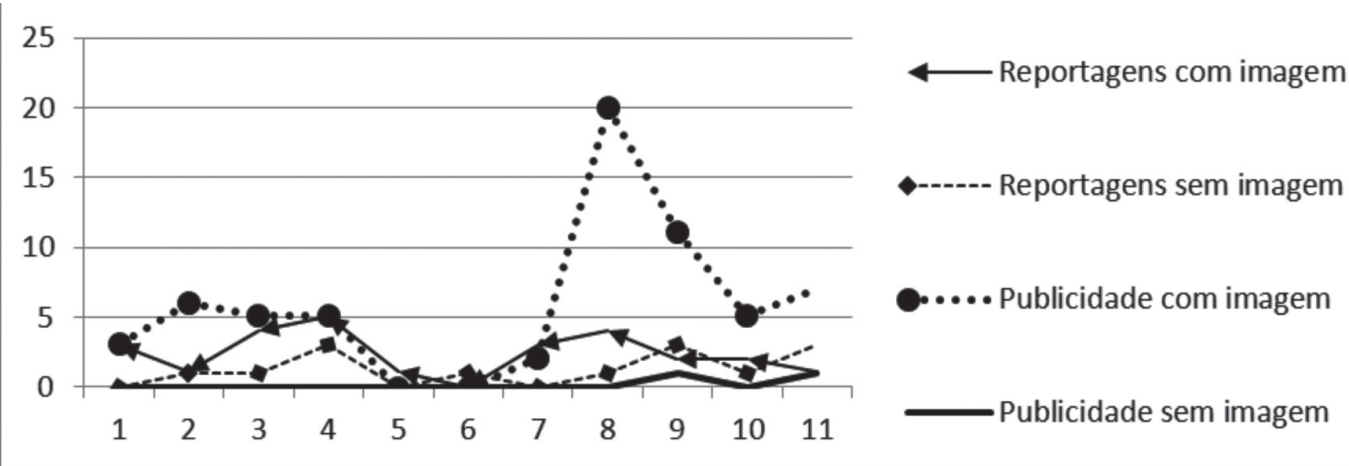


Outro dado que merece destaque refere-se aos registros midiáticos identificados e analisados, sendo $62,26 \%$ de publicidades veiculadas nos 11 dias referentes à delimitação temporal proposta; nestes, em apenas dois dias não haviam publicidades da data comemorativa do Dia dos Pais.

No entendimento de que a publicidade visa a comercialização de produtos e o aumento da lucratividade, as empresas investiram na associação da data comemorativa para divulgação dos seus produtos, que variaram desde eletrodoméstico e eletrônicos a aparelho auditivo, visita ao dentista e promoções que incluíram consulta em clínica de fertilização.

Após a leitura dos registros midiáticos, com identificação de matérias na delimitação temporal e aplicação da matriz de análise, realizou-se o agrupamento dos dados de acordo com a convergência temática representada, o que possibilitou o surgimento de quatro núcleos temáticos: gênero e papéis sociais; figura do pai na sociedade; utilização da figura paterna como estratégia de publicidade; e paternidade no cenário da violência.

\section{Gênero e papéis sociais}

Uma das reportagens descreveu a história de um modelo masculino encontrado morto, sendo a investigação policial conduzida para apuração de suicídio, embora seu pai tenha relatado ter sido morte acidental, fato que pode estar relacionado à imagem mental do homem associada à masculinidade, força e virilidade, não condizentes com fraqueza e derrota que podem estar relacionadas à motivação para a interrupção voluntária da vida. Isto conduz ao entendimento de que "a sociedade impõe ao homem uma postura de potência e invulnerabilidade, não lhe dando direito de transparecer suas fragilidades”.( Silva et al, 2012:566)
Duas reportagens retrataram casos de discriminações, tanto na ficção quanto na vida real. A primeira, apresentada na teledramaturgia, retratava o pai de um homem casado que mantinha relações homoafetivas, tentando negociar com a nora para que a situação não se tornasse pública. Na vida real, o preconceito se repetia no caso do menino, filho de casal homossexual, quando a criança fez dois presentes para o Dia dos Pais, e tendo a professora solicitado aos seus responsáveis que mantivessem este tipo de assunto restrito à casa da criança para evitar que ela sofresse preconceitos.

No caso, tanto essa criança quanto o personagem homossexual da novela ( no papel de filho), sofreram discriminação devido à fuga de parâmetros sociais predefinidos: o do homem heterossexual (Meyer,2010), e o do casamento entre homens e mulheres com fins procriativos. Com efeito, percebe-se que o pai, ao tentar encobrir o seu caso, visa proteger-se do preconceito, e também a sua família; e que a professora da criança busca o mesmo objetivo, demonstrando indícios de não estar preparada para lidar com a temática.

No que tange à informação, quando se emite uma mensagem, não é somente o que foi dito que produz significado, mas também o não-dito é dito, ou como poderia ter sido dito (Roso et al, 2002). No caso especifico da escola, entendeu-se que a reportagem estava em uma pequena seção do jornal. No entanto, a possível discriminação sofrida pela criança contra a orientação sexual dos pais, traz a uma série de questionamentos, dentre eles: Como foi a reação dos pais? Que proporção o caso tomou na escola? A direção tomou ciência? Houve discussão entre a equipe para melhor condução de casos futuros, objetivando evitar tanto o preconceito quanto promover os direitos sexuais? Respostas a estas indagações tornaram-se 
impossíveis diante do fato de que foram feitas a partir da descrição superficial do caso, mas que podem ser refletidas e repensadas em cenário de outras instituições escolares.

No registro midiático de três páginas, intitulado "Tem que ser macho", foi possível identificar diversas opções para a programação do Dia dos Pais, sendo que as atividades envolviam atitudes relacionados com a masculinidade (Figura1), tais como cardápios com refeições gordurosas e restaurantes com barbearias e mesas de sinuca, ratificando as características de invulnerabilidade previstas e destinadas socialmente ao homem.( Silva et al, 2012)

Na cultura ocidental, a imagem do homem é dotada de maior agressividade, e a da mulher, de muita suavidade, estando ela quase sempre realizando atividades relacionadas com a procriação ( Heilborn, 1997). Nesse sentido, Gilligan acrescenta que " o imperativo moral para as mulheres configura-se na obrigação de cuidar, já para os homens, aparece como o dever de respeitar as pessoas, protegendo-as de qualquer interferência em sua autonomia ou nos direitos à vida e à auto-realização" (Zoboli,2004:25).Sendo assim, enquanto a menina é presenteada com panelinhas e bonecas numa espécie de preparo para o cuidado da casa e dos filhos, opostamente, o menino ganha bolas, pipas e carrinhos, o que traduz a liberdade e o encaminhamento para o espaço público, cenário culturalmente associado à masculinidade, fato explícito em uma das reportagens mostrando que o pai deu o carro para o filho de 11 anos dirigir.

Tal fato leva a uma reflexão: se a herdeira fosse de sexo feminino, o pai faria o mesmo? Como possibilidade de resposta, poderia ser: "talvez não", porque os padrões culturais asseguram o espaço público ao homem, e o privado à mulher, devendo esta ser mais protegida e resguardada, marcando assim, ainda na infância, as respectivas trajetórias de vida de homens e mulheres (Heilborn, 1997).

\section{Imagem do pai na sociedade}

A perspectiva dos pais de que os filhos tenham futuro mais promissor que o deles (Bustame,2005), é explicitada no registro midiático onde o pai, em determinado momento do lançamento de seu livro, refere-se ao sucesso de uma filha como modelo e elogia, também, suas demais filhas.

$O$ fato de os pais serem imagem reflexo para os filhos homens (Bustame,2005) é retratado em cinco reportagens. Na primeira, inclusive na capa, traz o título "Em nome do pai/ Quando óleo e graxa são hereditários“, tanto os carros de família quanto o amor a estes são descritos como uma espécie de herança passada de pai para filhos. Na segunda reportagem, o fotógrafo relata ter sido influenciado na sua profissão por seu pai. Na terceira, um Chef de restaurante refere que na adolescência, seu pai o incentivou a cursar Gastronomia. A quarta reportagem, intitulada "De pai para filho", menciona um pai, ex-sócio de banco, estava abrindo um negócio para os filhos.

Numa quinta reportagem, um jogador de futebol posa para a foto com seu filho, sendo que ambos estão com o uniforme do time para o qual o pai trabalha, e em detalhe, na mão da criança, um boneco com o mesmo uniforme (Figura 2), desta maneira, o pai pode estar influenciando o filho a seguir sua carreira de jogador de futebol, e a criança pode estar, implicitamente, reproduzindo para o seu boneco o mesmo gesto, como possível cascata de projeções para as gerações futuras, fato que ratifica outra reportagem de um ex-jogador de futebol em que é possível problematizar tal situação, quando ele afirma que pais (homens e mulhe- 
res) influenciam seus filhos na opção de seguirem alguns passos profissionais, por exemplo, por meio de projeções mentais e visuais.

A inserção da mulher no mercado de trabalho, fez com que o pai deixasse de ser o provedor principal e conquistasse outros papéis e espaços (Crepaldi et al,2006). Na atualidade, o dito 'novo pai' não se restringe a copiar padrões antigos, associados ao papel exclusivo de provedor material; ao contrário, ele busca manter relação mais afetiva e vínculo com seus filhos, exercendo inclusive atividades de cuidado(Beltrame e Bottoli,2010; Freitas, Coelho e Silva,2007).

Um torcedor de futebol posa para foto beijando o filho que não viu nascer, por estar preso em outro país na ocasião do seu nascimento, o que sensibiliza implicitamente o leitor para a importância da participação do pai no momento do parto.

Em outros registros midiáticos, o novo modelo de pai mais participativo e afetivo também é percebido, iniciando pelo desejo e planejamento da paternidade descrito por um ex-padre, que pode ser tido como uma forma de exercer os direitos reprodutivos. E em outra reportagem, visando auxiliar a filha a melhorar o rendimento escolar, o pai escreve um livro de contos para estudar junto a ela.

A natureza da palavra "cuidado" inclui duas significações: na primeira, tem-se a atitude de desvelo, solicitude e atenção para com outra pessoa; na segunda remete a uma preocupação proveniente do envolvimento e da afetividade com o outro por parte de quem cuida, permitindo que se observe que "cuidar é mais que um ato singular; é modo de ser, a forma como a pessoa se estrutura e se realiza no mundo"( Zoboli,2004:22).

A representação imagética do pai mostrando-se afetivo e participativo na vida do filho, também é percebida em reportagem do homem que presta cuidados ao filho deficiente físico e, ainda, possibilita que o mesmo participe de uma corrida, auxiliando-o, ao empurrá-lo na cadeira de rodas (Figura 3), e em outra matéria, o pai, um ator famoso, está à procura de escola para seus filhos.

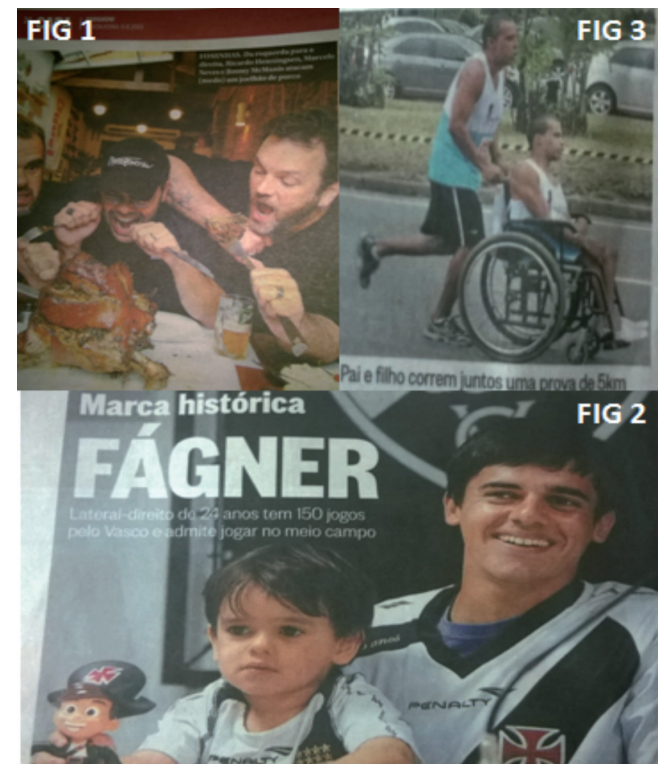

Nos registros midiáticos, o perfil é apresentado mais de uma vez quando um garçon é eleito por jornais de bairro como o melhor da zona Sul do Rio de Janeiro. Seu sucesso na eleição deve-se ao seu comportamento em compartilhar com a mulher o cuidado da casa e dos filhos. Nesta perspectiva, observa-se que a complementaridade entre os sexos, descrita por Carol Gilligan, se faz presente, pois o sucesso profissional, ao ser atribuído ao casal, demonstra que " a relação entre a justiça e o cuidado são, pode-se dizer, as duas faces do ‘juízo moral' que não é assexuado, mas antes, tem duas identidades equivalentes e legítimas"( Marinho,2004:77).

A relação positiva entre pais e filhos é representada sob diversas formas. Em três re- 
portagens, pais falecidos são rememorados por meio da imagem fotográfica de momentos felizes com seus filhos, e até mesmo por depoimento repleto de elogios, o que conduz ao juízo de valor de que se tratavam de bons pais.

Alguns pais famosos e de representatividade social, como ministro, posam com sua família, o que pode indicar o papel positivo da paternidade, e a figura do bom pai refletindo favoravelmente como tipo-ideal.

É registrada por colunista do jornal, a visita à casa de seu pai quando se surpreendeu ao descobrir que este escreve em cadernos, trechos de sua vida, o que possibilitou perceber que estes homens gostariam que seus feitos e histórias em vida, fossem lembrados após a morte.

A maior afetividade e participação do pai nos cuidados com o filho torna-se presente inclusive em uma reportagem cujo caráter exclusivamente biológico parece não ser o mais importante na assunção do papel de pai. O registro midiático "Filiação além de laços sanguíneos", cita que um homem que não possui laços consangüíneos com determinada criança, exerce "uma espécie de guarda compartilhada" com a mãe biológica do menino.

O apego é descrito como fundamental para a sobrevivência e desenvolvimento da criança, sendo visto como laço dos pais com o bebê, que influencia por toda a vida, a qualidade de laços futuros com outros indivíduos, sabe-se também que o comportamento paterno é influenciado, positiva ou negativamente, por fatores como: os cuidados que recebeu de seus próprios pais, a cultura em que se insere, o desejo da gravidez ou de seu planejamento, o comportamento dos profissionais de saúde que o atenderam e a qualidade da assistência ao parto.( Klaus e Kennel,1992)
Destarte, parte-se deste princípio para a sensibilização dos profissionais de saúde no sentido de auxiliarem a inclusão do pai precocemente na vida do filho, considerando a necessidade de qualificação da assistência pré-concepcional, pré-natal, no parto e durante os primeiros anos de vida da criança, visando fortalecer o vínculo entre pais e filhos, já reconhecido como fundamental para o crescimento e desenvolvimento saudável da criança, e garantir o exercício mais pleno possível do direito à reprodução responsável.

Por fim, a divulgação de uma palestra com a chamada: "O que é ser pai", a ser realizada em um shopping, no mês do Dia dos Pais. Esta traz a reflexão acerca da procura do homem contemporâneo por aprender como desempenhar seu novo papel social, ao se tornar pai.

\section{Utilização da figura paterna como estraté- gias de publicidade}

O Dia dos Pais é lembrado, inclusive tendo direito à dedicação de programa televisivo específico, assim como a sugestão de inúmeras formas e locais para comemorá-lo e as formas de presentear os pais pela data. Neste contexto, insere-se a publicidade visando dar lucratividade às empresas com a data comemorativa. Corroborando esta afirmativa, um dos registros midiáticos descreve a perspectiva de famílias gastarem mais com o presente do Dia dos Pais, do que com o presente do Dia das Mães.

A grande quantidade de publicidade abordando a temática contraria a descrição (Noblat,2008) de que o jornal é (ou deveria ser) o espelho da consciência critica da sociedade, e não uma oportunidade de negócios para proveito próprio, como no caso de acionistas e fornecedores. As empresas que parecem ter utilizado a data comemorativa na tentativa de aumentar sua lucratividade, variaram desde 
empresas do ramo de eletrônicos, de gêneros alimentícios, até escolas, dentistas e empresas de planos de saúde.

As publicidades funcionam da seguinte forma: "As pessoas compram os produtos 'certos' esperando que esses produtos signifiquem certo status social, estilo de vida, etc." (Roso et al, 2002:84). Neste sentido, a tentativa de atingir o consumidor se dá pela empatia. Para isso, na maioria das publicidades analisadas, as empresas utilizam-se da emoção e da relação de afetividade entre pais e filhos, deixando transparecer que investem em padrões de normalidade, socialmente impostos, o que conduz ao reforço das iniquidades de gênero e raciais.

Corrobora esta afirmativa o fato de que em $88,63 \%$ das imagens, aparecerem personagens da raça branca - pais com filhos, e $76 \%$ - serem representados por meninos. Nas imagens de família, a parceira do pai é representada por uma mulher, nunca por outro homem. Estes três achados podem estar remetendo o possível cliente ao estereótipo valorizado e esperado: o do homem branco e heterossexual (Meyer,2010).

Os meios de comunicação em massa trazem a interação com diversas culturas; no entanto, os símbolos das publicidades quando contribuem para reforçar relações de dominação e exclusão, tornam-se problema, o que viola o exercício de cidadania das pessoas com traços culturais ou físicos específicos, culminando em desvalorização e discriminação (Roso et al, 2002).

\section{Paternidade no cenário da violência}

Durante o período analisado, a violência aparece ao redor da paternidade em cinco eventos distintos, e apenas em um caso no cenário de violência doméstica em que o advogado de defesa de pai e madrasta acusados pela morte de criança, busca novas vertentes para embasar o laudo de acusação. Em três reportagens a comemoração do Dia dos Pais torna-se propícia para rememoração e descrição de indignação, ao reivindicar por justiça, homem descrito como pai trabalhador, morto por policiais. Os demais registros midiáticos repercutem a dor e o sofrimento dos pais frente à morte dos filhos.

Este contexto de violência associa-se ao perfil esperado do homem ocidental, vinculado à agressividade (Heilborn, 1997), o que promove certa ideia de que o homem seja psicologicamente forte, articulando à masculinidade, à invulnerabilidade, fatores que influenciam nos padrões de morbimortalidade (Silva et al, 2012).

Esta afirmativa pode ser comprovada ao se analisar o ano de 2011 através dos dados estatísticos sobre mortalidade(Brasil,2014), em que se observa que a causas externas (incluindo acidentes e violências), são responsáveis pelo segundo lugar no que tange a mortalidade no público masculino.

\section{CONCLUSÃO}

Nos registros midiáticos analisados foram percebidas situações que se refletiram nas iniquidades de gênero, permeando os valores socialmente atribuídos ao sexo masculino, assim como no investimento empresarial em torno da data comemorativa do Dia dos Pais para aumentar os ganhos, retratando ainda, a violência no cenário da paternidade.

As características da nova paternidade foram percebidas nas reportagens analisadas, $o$ que pode tanto estar refletindo uma tendência sociocultural, quanto estar influenciando para mudanças positivas nestes padrões que estimulam o homem a exercer o tipo de paternidade não restrita ao provimento financeiro e na obrigação legal. 
Aos profissionais de saúde, esta pesquisa possibilita, além de reconhecer e explorar as vertentes que regem a temática, repensar valores e condições predefinidas, que podem estar limitando o exercício do direito de ser pai de forma plena.

É oportuno, ainda, repensar o cuidado na Saúde do Homem pautada na redução das iniquidades de gênero, incluindo necessidades de saúde, não atendidas pelo modelo biomédico. Neste sentido, cabe pensar na promoção de saúde garantindo direitos como objetivo real, e na área da saúde sexual e reprodutiva, pensar na importância de investir em ações que garantam o exercício do direito à reprodução e à paternidade plena, com práticas inclusivas que estimulem a participação do sexo masculino no planejamento e cuidado com a sua família.

\section{REFERÊNCIAS}

- Associação Nacional de Jornais. Maiores Jornais do Brasil.(2013). Medios impresos. Recuperado em http:// www.anj.org.br/a-industria-jornalistica/jornais-nobrasil/maiores-jornais-do-brasil.

- Beltrame, G.R., \& Bottoli C. (2010). Retratos do envolvimento paterno na atualidade. Barbarói, Santa Cruz do Sul. 32-205-226.

- Bustamante, V. (2005). Participação paterna no cuidado de crianças pequenas: um estudo etnográfico com famílias de camadas populares. Saúde Pública. 21(6),1865-1874.

- Campos, E.A, Melo, L.P. \&, Farias, D.F. (2012). Los significados de la paternidad para los hombres jóvenes en los alrededores de São Paulo-Brasil. Cultura de los Cuidados). 16, 33. Recuperado de http://dx.doi. org/10.7184/cuid.2012.33.08

- Crepaldi, M.A., Andreani, G., Hammes, O.S., Ristof, C.D., \& Abreu, S.R.A. (2006). Participação do pai nos cuidados da criança, segundo a concepção de mães. Psicologia em Estudo, 11(3),579-587.

- Freitas. W.M.F., Coelho, E.A.C., \& Silva, A.T.M.C. (2007). Sentir-se pai: a vivência masculina sob o olhar de
gênero.Cad. Saúde Pública. 23(1),137-145. Recuperado em http://www.scielo.br/pdf/csp/v23n1/14.pdf.

- Gil, A.C. (2008). Métodos e técnicas de pesquisa social. 6. ed. São Paulo:Atlas.

- Heilborn, M.L. (1997). Gênero, sexualidade e saúde. In: Saúde, Sexualidade e Reprodução - Compartilhando responsabilidades. Rio de Janeiro: EdUERJ; Recuperado en http://www.clam.org.br/uploads/publicacoes/ 1139 Genero-Sexualidade-Saude.pdf

- Hennigen, I., \& Guareschi, N.M.F. (2002). A paternidade na contemporaneidade: um estudo de mídia sob a perspectiva dos estudos culturais. Psicologia e Sociedade, 14(1),44-68.

- Hobsbawm, E., \& Ranger, T. (orgs.). (1984). A invenção das tradições. Rio de Janeiro: Paz e Terra. Recuperado en http://copyfight.me/Acervo/livros/HOBSBAWM,\%20 Eric\%20-\%20Introduc\%CC\%A7a\%CC\%83o\%20do\%20 livro\%20A\%20invenc\%CC\%A7a\%CC\%83o\%20das\%20 Tradic\%CC\%A7o\%CC\%83es.pdf>.

- Kuhnen, T.A. (2010). A Ética do cuidado como alternativa à ética de princípios: divergências entre Carol Gilligan e Nel Noddigns. Ethic@ - Revista Internacional de Filosofia da Moral. 9(4),155-168.

- Klaus, M.H., \& Kennel, J.H. (1992). Pais/bebê: a formação do apego. Porto Alegre: Artes Médicas.

- Marinho, M. (2004). Olhares femininos sobre a ética: Carol Gillingan e Nel Noddings. Intervenção Social, 29,71-82.

- Marshall, L. (2003).O Jornalismo na era da publicidade. São Paulo: Summus.

- Meyer, D.E. (2010). Gênero e educação: teoria e política. In: Louro, G.L., Felipe, J., Goellner, S.V. (orgs.). Corpo, gênero e sexualidade: um debate contemporâneo na educação. 6. ed. Petrópolis: Vozes.

- Ministério da Saúde (Br) Secretaria Executiva. Tabnet/ Datasus [acesso em 10 Jan. 2014], Informações de Saúde, Estatísticas Vitais. Recuperado en http://www0.rio. rj.gov.br/tabnet/

- Noblat, R. (2008). A arte de fazer um jornal diário.7. ed. 2. reimpreensão. São Paulo: Contexto.

- O Globo. Dia dos Pais. (2014). Diario O Globo. Recuperado em http://memoria.oglobo.globo.com/ 


\section{Cultura de las Cuidados}

institucional/promocoes/dia-dos-pais-9260840

- Oliveira, A.G., \& Silva, R.R. (2011). Pai contemporâneo: diálogos entre pesquisadores brasileiros no período de 1998 a 2008. Psicol.Argum, 29(66),353-360.

- Portal, G.L. (2013). Saiba como o dia dos pais é comemorado pelo mundo. Recuperado em http:// g1.globo.com/dia-dos-pais/2013/noticia/2013/08/saibacomo-o-dia-dos-pais-e-comemorado-pelo-mundo.html

- Roso, A., Srey, M.N., Guareschi, P., \& Bueno, S.M.N. (2002). Cultura e ideologia: a mídia revelando estereótipos raciais de gênero. Psicologia e Sociedade, 4(2),74-94.

- Sá-Silva, J.R., Almeida, C.D., \& Guindani, F. (2009). Pesquisa documental: pistas teóricas e metodológicas.
Rev Brasileira de História e Ciências Sociais, 1(1),1-15.

- Santaella, L., \& Noth, W. (2008). Imagem - cognição, semiótica, mídia. São Paulo: Iluminurias.

- Silva, P.A.S., Furtado, M.S., Guilhon, A.B., Souza, N.V.D.O. \& David, H.M.S.L. (2012). A saúde do homem na visão dos enfermeiros de uma unidade básica de saúde. Esc Anna Nery Rev Enf, 16(3),561-568.

- Sodré, M., \& Ferrari, M.H. (1986). Técnica de reportagem - notas sobre a narrativa jornalística. São Paulo: Summus.

- Zoboli, E.L.C.P. (2004). A redescoberta da ética do cuidado: o foco e a ênfase nas relações. Rev Esc. Enferm. USP, 38(1),21-7.

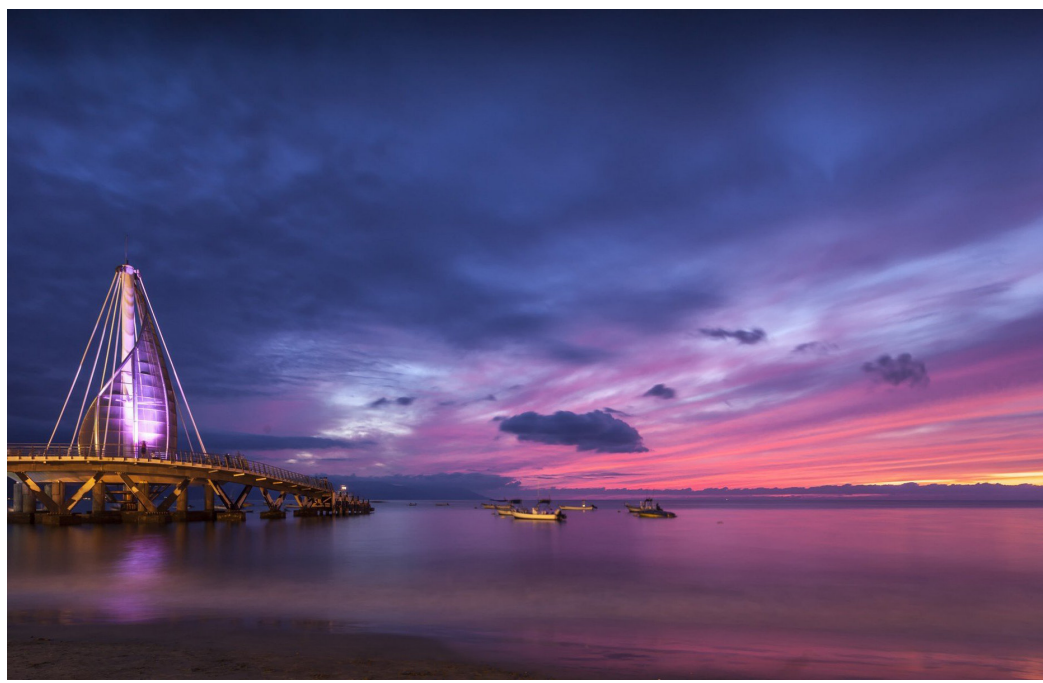

